\title{
Erratum to: Influence of family history of major depression, bipolar disorder, and suicide on clinical features in patients with major depression and bipolar disorder
}

\author{
Alessandro Serretti - Alberto Chiesa $\cdot$ Raffaella Calati $\cdot$ Sylvie Linotte $\cdot$ Othman Sentissi $\cdot$ \\ Konstantinos Papageorgiou - Siegfried Kasper · Joseph Zohar - Diana De Ronchi · \\ Julien Mendlewicz $\cdot$ Daniela Amital $\cdot$ Stuart Montgomery $\cdot$ Daniel Souery
}

Published online: 30 July 2013

(c) Springer-Verlag Berlin Heidelberg 2013

\section{Erratum to: Eur Arch Psychiatry Clin Neurosci}

(2013) 263:93-103

DOI 10.1007/s00406-012-0322-y

In the original publication, the affiliation of the third author R. Calati is incorrect. The author's correct affiliation is: IRCCS Centro S. Giovanni di Dio, Fatebenefratelli, Brescia, Italy.

The online version of the original article can be found under doi:10.1007/s00406-012-0322-y.

\section{A. Serretti · A. Chiesa $(\bowtie) \cdot$ D. De Ronchi Institute of Psychiatry, University of Bologna, Viale Carlo Pepoli 5, 40123 Bologna, Italy e-mail: albertopnl@yahoo.it}

\section{A. Chiesa}

Section of Pharmacology, Department of Clinical and Experimental Medicine and Pharmacology,

University of Messina, Messina, Italy

\section{R. Calati}

IRCCS Centro S. Giovanni di Dio, Fatebenefratelli,

Brescia, Italy

\section{S. Linotte}

Fonds de la Recherche Scientifique (FNRS),

Laboratoire de Neurologie Expérimentale,

Université Libre de Bruxelles, Bruxelles, Belgium

\section{O. Sentissi}

Département de Santé Mentale et de Psychiatrie, Service de Psychiatrie Générale, Hôpitaux Universitaires de Genéve (HUG), Geneve, Switzerland
K. Papageorgiou $\cdot$ S. Kasper

Department of Psychiatry and Psychotherapy,

Medical University Vienna, Vienna, Austria

J. Zohar

Chaim Sheba Medical Center, Tel-Hashomer, Israel

J. Mendlewicz

Université Libre de Bruxelles, Brussels, Belgium

D. Amital

Department of Psychiatry 'B', Ness-Ziona Mental Health Center,

Tel-Aviv University, Ness-Ziona, Israel

\section{S. Montgomery}

Imperial College School of Medicine, London, UK

D. Souery

Laboratoire de Psychologie Medicale,

Centre Européen de Psychologie Medicale,

Université Libre de Bruxelles and Psy Pluriel,

Brussels, Belgium 